\title{
Tooth color alteration after debonding in orthodontic patients with adhesive removal using composite bur or tungsten carbide bur: a single center, randomized controlled clinical trial
}

Alteração da cor do dente após descolagem de braquetes em pacientes ortodônticos pela remoção de adesivo usando broca de compósito ou broca carbide de tungstênio: ensaio clínico unicêntrico randomizado e controlado

Amir Hooman SADRHAGHIGHI ${ }^{1}$, Amir MOHAMMADI ${ }^{1}$, Tannaz Adollahzadeh BAGHAEI ${ }^{1}$, Hamed ALIPOUR ${ }^{2}$

1 - Department of Orthodontics - Tabriz University of Medical Sciences - Tabriz - Iran

2 - Tabriz University of Medical Sciences - Tabriz - Iran.

\begin{abstract}
Objective: The objective of this study was to determine whether recently developed fiber reinforced composite burs provided better results by comparing tooth discoloration after debonding of orthodontic brackets. Material and Methods: A split-mouth, randomized controlled trial was carried out in one orthodontic office; including 23 patients with intact, vital and caries-free four upper incisors aged 12 to 30 years who completed their fixed orthodontic treatment. For each patient, upper central and lateral incisors on each side of the mouth were randomly selected to remove the adhesive with either a tungsten carbide bur (TC) ( $\mathrm{n}=$ 46) or a fiber-reinforced composite bur (FC) $(n=46)$. Color evaluation of each tooth was conducted at two time points: immediately after finishing and polishing procedure and two months afterwards. The primary outcome would be the amount of color change in each group during the post treatment phase. The participants, the person assessing the color change and the statistician were blinded to TC group assignment. Color changes in each group were analyzed with the Paired T-test. The color change corresponding to the resin removal method was also statistically analyzed with the Independent T-test at $\alpha=0.05$ as the level of significance. Results: 86 teeth, 43 in each group, were analyzed. The $\Delta \mathrm{E}$ value was $3.713 \pm 1.161$, for teeth finished TC and $2.114 \pm 0.514$ for teeth finished with FC $(\mathrm{p}<0.01)$. Conclusion: Adhesive removal with FC bur results in a more color-resistant tooth surface in comparison with tungsten carbide bur.
\end{abstract}

\section{KEYWORDS}

Tooth discoloration; Dental debonding; Fixed orthodontic appliances.

\section{RESUMO}

Objetivo: O objetivo deste estudo foi determinar se as brocas de material compósito reforçadas com fibras, recentemente desenvolvidas, proporcionam melhores resultados, pela comparação da descoloração dentária após a remoção de braquetes ortodônticos. Material e Métodos: Um ensaio clínico controlado randomizado com boca dividida foi realizado em um consultório ortodôntico, incluindo 23 pacientes, com idade entre 12 e 30 anos, com incisivos superiores intactos, vitais e livres de cárie, que completaram o tratamento ortodôntico com aparelho fixo. Para cada paciente, incisivos centrais e laterais superiores de cada lado da boca foram selecionados aleatoriamente para remover o adesivo ortodôntico com uma broca carbide de tungstênio (TC) ( $n=46)$ ou uma broca de compósito reforçada com fibra $(\mathrm{FC})(\mathrm{n}=46)$. A avaliação da cor de cada dente foi realizada em dois momentos: imediatamente após o acabamento e polimento e dois meses após. O resultado primário foi a quantidade de mudança de cor em cada grupo durante a fase pós-tratamento. Os participantes, a pessoa que avaliou a mudança de cor e o estatístico não tinham conhecimento da atribuição ao grupo TC. As mudanças de cor em cada grupo foram analisadas com o teste-t pareado. A mudança de cor correspondente ao método de remoção da resina também foi analisada estatisticamente com o teste- $t$ independente considerando um nível de significância $\alpha=0,05$. Resultados: foram analisados 86 dentes, 43 em cada grupo. $\mathrm{O}$ valor de $\Delta \mathrm{E}$ foi $3,713 \pm 1,161$, para dentes finalizados com broca TC e 2,114 \pm 0,514 para dentes finalizados com broca FC (p <0,01). Conclusão: A remoção do adesivo com broca $\mathrm{FC}$ resulta em uma superfície de dente mais resistente à cor em comparação com a broca carbide de tungstênio.

\section{PALAVRAS-CHAVE}

Descoloração de dente; Descolagem dentária; Aparelhos Ortodônticos Fixos. 


\section{INTRODUCTION}

$\mathrm{E}$ sthetics is one of the main goals in orthodontic treatment, although, studies show orthodontic patients are sometimes dissatisfied with their dental look. Especially, disappointment with the tooth color urges patients to whiten their teeth at the end of treatment [1]. Undoubtedly fixed orthodontic treatment damages dental enamel irreversibly [2,3]. These irreversible effects could cause clinical discoloration, which may originate from two causes: 1 . the resin removal procedures involving instrumentation with various rotary devices and 2. the infiltration of resin tags in the enamel at depths up to $50 \mu \mathrm{m}$ [4].

The remaining resin tags would change enamel color by two means: first; altering the reflected light. Resin-tags penetrating into the empty enamel rods could cause alteration in the enamel refractive index and therefore in the reflected light. Subsequently, the color parameters may change [5-7]. The second possible effect of resin tags is the combination of extrinsic and intrinsic color change. Many parameters may affect this process, e.g., type of adhesive materials, clinical handling of the material, diet and oral hygiene of patients [8].

Unfortunately enamel changes and texture alterations cannot be restored by current methods of adhesive removal and it may be associated with tooth discoloration $[9,10]$. Different methods of resin removal have been suggested; ultrafine diamond bur, ultrasonic scaler, tungsten carbide bur, and Sof-Lex disks [11], CO2 laser [12] and fiber-reinforced composite bur [13]. Until recently, low speed tungsten carbide bur has been suggested by many authors [14-18], however, there still is a need for finding methods to attain a smooth surface after removal of fixed orth $\neg$ odontic appliances [3].

After the advent of fiber reinforced composite burs for resin removal, some studies reported that they create smoother texture in comparison with the carbide bur, even smoother than intact enamel [13]. These burs are perceived as substitutes for conventional methods since the results are similar to prophylaxis paste while their application is much easier [19].
Kamber et al has reported that fixed orthodontic treatment appears associated with tooth color change. In all the studies assessed in this review, the endpoint of outcome timing was as a maximum of one week after debonding [20]. Change in optical properties of the enamel during the post-debonding period is a practical method for evaluation of tooth appearance alterations associated with routine orthodontic treatment. Taking into consideration that few studies have investigated this parameter, the aim of this study was to evaluate the post-debonding color change after polishing by tungsten carbide bur compared to that of fiber reinforced composite bur.

\section{MATERIAL AND METHODS}

This study was a split-mouth, randomized controlled trial with 1:1 allocation ratio conducted in Tabriz, Iran. Ethical approval was granted from the ethics committee of Tabriz University of Medical Sciences (Iranian Registry of Clinical Trials, IRCT, submission code: IR.TBZMED. REC.1395.1176). The methods did not change after initiation of the study. The protocol was not published before study commencement.

Twenty-three consecutive patients with completed orthodontic treatment were recruited at one private orthodontic office from April 2014 to February 2015. The subjects were provided with information leaflets describing the study protocol, and then written informed consent was obtained. They were selected by application of the following criteria:

1. Intact, vital and caries-free four upper incisors evident after debonding;

2. 12 to 30 years old at the time of recording data;

3. Acceptable oral hygiene.

\section{Interventions:}

According to the documentation of each patient, all the teeth underwent the same bonding procedure by Transbond XT $(\AA$ adhesive resin (3M/Unitek, Monrovia, CA, USA). For each patient, upper central and lateral incisor of one side of the mouth was randomly assigned to be finished with a 12-blade tungsten carbide bur 
(Busch, Düsseldorf, Germany) which was secured on a low-speed contra-angle handpiece (TC group, $n=23$ ). The adequacy of resin removal was confirmed with visual inspection and examination with an explorer [9]. On the other side of the mouth, the upper incisors were finished with a fiber-reinforced composite bur (Stain buster ${ }^{\circledR}$, Abrasive Technology, Ohio, USA) similarly with a low-speed contra-angle handpiece (FC group, $\mathrm{n}=23$ ). Resin removal procedure was also approved by the same visual examination.

All teeth including the upper incisors of both groups were later polished via a rubber cup and pumice and then rinsed enough to ensure no pumice remained on the tooth surfaces. The finishing and polishing procedures were conducted by the same clinician.

Color evaluation of the upper central and lateral incisors was performed with a reflectance spectrophotometer (SpectroShade, MHT, Italy) right after debonding and 2 months afterward at a follow up appointment. Color evaluation was established on CIE (Commission Internationale de l'Eclairage) L*a*b* color system. L represents lightness; $\mathrm{a}$ and $\mathrm{b}$ illustrate chroma in the redgreen and blue-yellow axis respectively.

After calibration of the spectrophotometer, a sterile and disposable cover was attached to the head of it. The head was held at a right angle to the middle third of the labial surface of each tooth and then color assessment was conducted by a trained clinician. Each assessment was repeated twice, and the mean result was reported. To assess inter-examiner reliability, fifteen measurements were conducted twice another examiner.

Using the following formula, the color difference between end-treatment and follow up appointment was calculated:

$$
\Delta E=\left[\left(L_{2}-L_{1}\right)^{2}+\left(a_{2}-a_{1}\right) 2+\left(b_{2}-b_{1}\right)^{2}\right]^{1 / 2}
$$

L1, a1 and b1 represents the color parameters at the debonding appointment and L2, a2 and b2 are the measurements made at the follow up appointment.

\section{Sample size calculation:}

To calculate sample size a pilot study including 5 patients was conducted. With mean difference of color changes $(\Delta \mathrm{E})$ between $\mathrm{TC}$ group and FC group being 1.05 $\pm 1.67,41$ teeth in each group would be necessary to ensure a power of $80 \%$ at a significance level of $5 \%$. To enhance the power, 46 teeth were assigned to each group.

\section{Randomization and concealment:}

For each patient, the upper incisors of each side were randomly allocated to either the FC or TC group via a computer-generated list (RandList ${ }^{\circledR}$; DatInf GmbH, Tübingen, Germany). Allocation concealment was accomplished by telephone randomization when a participant entered the study.

\section{Blinding:}

The patients, the clinician in charge of measuring and entering the data and the statistician were blinded to the type of intervention; however, it was unfeasible to blind the clinician conducting the adhesive removal procedure. The level of significance was set at $\mathrm{P}=0.05$.

\section{Statistical analysis:}

Descriptive statistics were calculated. The inter-examiner reliability of the color measurements was evaluated with the intraclass correlation coefficient (ICC) at a 95\% confidence interval. Color changes in each group were analyzed with the Paired T-test. The color change corresponding to the resin removal method was also statistically analyzed with the Independent T-test at $\alpha=0.05$ as the level of significance.

\section{RESULTS}

Twenty-three patients were enrolled in the study (92 teeth). One of the patients refused to attend the follow up appointment (lost to follow up) and two upper lateral incisors were excluded due to build-up restoration following the appliance removal (figure 1). The study was concluded with 86 teeth. The baseline data are illustrated in table I. The mean age was $22 \pm 1.7$ ranging between 12 and 30. Data regarding color change in each group are presented in table II. 


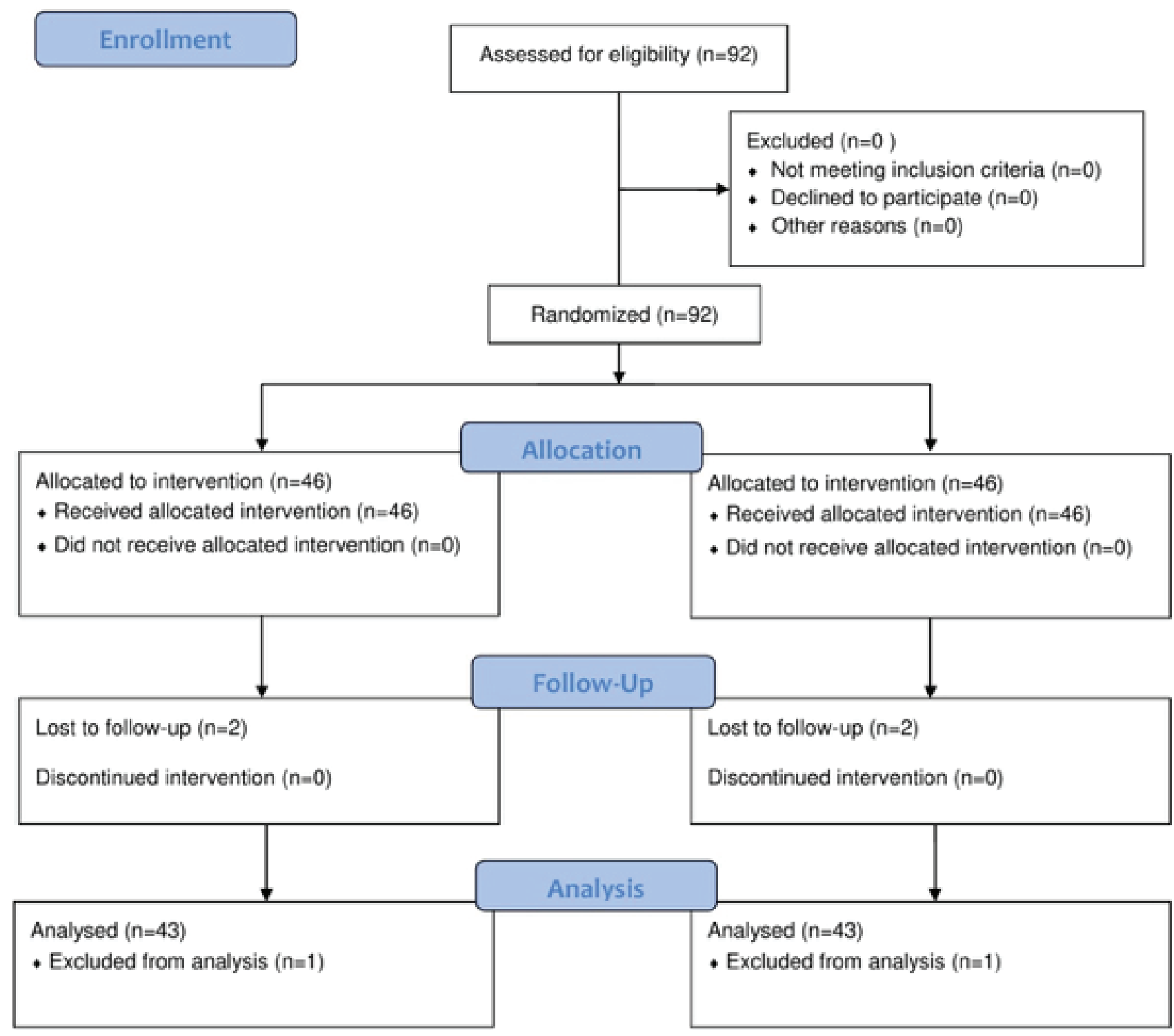

Figure 1 - CONSORT flow diagram.

Table I - Baseline data.

\begin{tabular}{|c|c|c|c|c|}
\hline & & $\mathrm{FC}(n=43)$ & FC group $(n=43)$ & Total $(n=86)$ \\
\hline \multicolumn{2}{|c|}{ Age (years) } & $22 \mathrm{yrs}, 8 \mathrm{mo}$ & $23 \mathrm{yrs}, 2 \mathrm{mo}$ & $22 \mathrm{yrs}, 11 \mathrm{mo}$ \\
\hline \multirow{2}{*}{ Gender } & Male & 2 & 2 & 4 \\
\hline & Female & 21 & 21 & 42 \\
\hline \multicolumn{2}{|c|}{ Central incisors } & 22 & 22 & 44 \\
\hline \multicolumn{2}{|c|}{ Lateral incisors } & 21 & 21 & 42 \\
\hline
\end{tabular}

Table II - The Mean, standard deviation, minimum and maximum values of the Groups L, lightness; a, red/green; b, blue/yellow; 1 and 2 subscripts denote measurements made at debonding and follow up sessions respectively.

\begin{tabular}{|c|c|c|c|c|c|c|c|}
\hline & Mean $\pm S D$ & Min & Max & & Mean $\pm S D$ & Min & Max \\
\hline \multicolumn{4}{|c|}{ TC group } & \multicolumn{4}{|c|}{ FC group } \\
\hline L1 & $72.85 \pm 2.67$ & 63 & 77 & L1 & $72.33 \pm 2.56$ & 68 & 78.50 \\
\hline a1 & $3.59 \pm 1.14$ & 1.52 & 6.34 & a1 & $3.75 \pm 2.74$ & 2.10 & 5.74 \\
\hline b1 & $17.40 \pm 2.13$ & 12.41 & 23.50 & b1 & $18.56 \pm 1.84$ & 14.04 & 22.10 \\
\hline L2 & $70.41 \pm 2.80$ & 59.90 & 75 & L2 & $71.05 \pm 2.74$ & 66.40 & 78.20 \\
\hline a2 & $3.28 \pm 0.86$ & 1.75 & 4.94 & a2 & $3.87 \pm 0.97$ & 2.17 & 5.66 \\
\hline b2 & $19.48 \pm 2.72$ & 12.72 & 24.97 & b2 & $19.54 \pm 1.82$ & 15.08 & 22.60 \\
\hline
\end{tabular}


Normal distribution of CIE parameters in each group was confirmed with the KolmogorovSmirnov test.

Mean differences between debonding and follow up values for each group were calculated using the paired t-test (table III and figure 2). The changes in $L^{*}$ and $b^{*}$ parameters were statistically significant.

Table III - Changes in CIE parameters within each group by means of the Paired T-test.

\begin{tabular}{ccccccc}
\multirow{5}{*}{ TC group } & & $\mathbf{n}$ & Mean \pm SD & Min & Max & P-value \\
& L1-L2 & 43 & $2.44 \pm 1.05$ & 2.12 & 2.76 & 0.001 \\
& a1-a2 & 43 & $0.27 \pm 0.96$ & -0.03 & 0.56 & 0.074 \\
& b1-b2 & 43 & $-2.07 \pm 1.70$ & -2.59 & -1.55 & 0.001 \\
& L1-L2 & 43 & $1.28 \pm 0.82$ & 1.03 & 1.53 & 0.001 \\
\multirow{4}{*}{ FC group } & a1-a2 & 43 & $-0.13 \pm 0.93$ & -0.41 & 0.16 & 0.376 \\
& b1-b2 & 43 & $-0.98 \pm 0.79$ & -1.23 & -0.74 & 0.001
\end{tabular}

1. N, number of subjects; SD, standard deviation; Min, minimum; Max, maximum.

2. A p-value less than .05 was considered statistically significant. 3. L, lightness; a, red/green; b, blue/yellow; 1 and 2 subscripts denote measurements made at debonding and follow up sessions respectively.

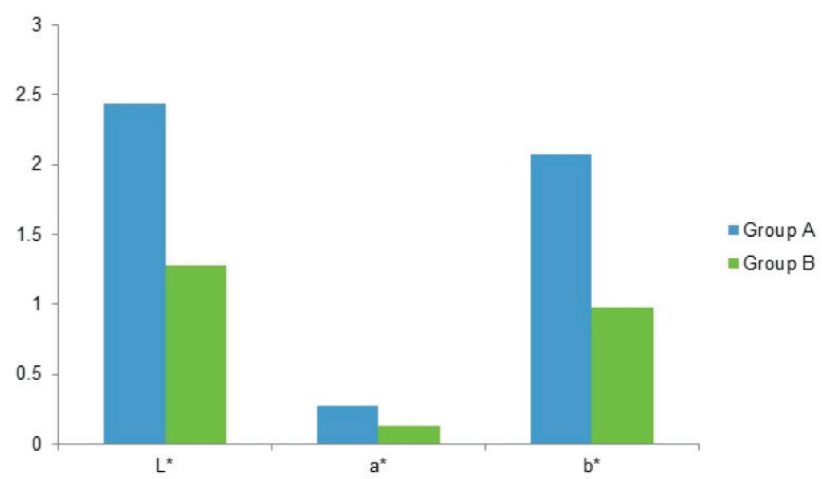

Figure 2 - Comparison of absolute values of mean differences between the two groups.

The results of the independent t-test revealed that $\Delta \mathrm{E}$ value for $\mathrm{FC}$ group is more than TC group and the difference is statistically determinate $(\mathrm{p}<0.05)$.

The mean ICC for inter- and intraexaminer reproducibility confirmed high mean percentages of agreement (table IV and V).
Table IV - Comparison of $\Delta \mathrm{E}$ values between groups by means of the independent t-test.

\begin{tabular}{|c|c|c|c|}
\hline & N & Mean $\pm S D$ & P-value \\
\hline TCgroup & 43 & $3.713 \pm 1.161$ & \multirow{2}{*}{0.001} \\
\hline FCgroup & 43 & $2.114 \pm 0.514$ & \\
\hline
\end{tabular}

1. N, number of subjects; SD, standard deviation.

2. A p-value less than .05 was considered statistically significant.

Table V - Inter-examiner Reliability Estimated on First Measurement Occasion.

\begin{tabular}{|c|ccc|} 
& Measurement & $\begin{array}{c}\text { Inter-observer } \\
\text { reliability }\end{array}$ & P-value \\
\hline & LCC $(95 \%$ CI) & $0.99(0.98-0.99)$ & 0.001 \\
& a & $2114 \pm 0.514$ & 0.001 \\
& b & $0.97(0.94-0.98)$ & 0.001 \\
\hline
\end{tabular}

1. n, number of subjects; ICC, intra-class correlation coefficient; $\mathrm{Cl}$, confidence interval.

2. A p-value less than 0.05 was considered statistically significant.

\section{DISCUSSION}

The results of this study demonstrate tooth color alteration 2 months after appliance removal, which means the final tooth color is not what we see immediately after debonding. The discoloration was higher in the group finished by a tungsten carbide bur, which in some cases is beyond the limit of clinically noticeable amount $(\Delta E>3.6)$. In detail, changes in $L^{*}$ and b* parameters in TC group was significantly higher than FC group.

The final result of orthodontic treatment is not merely about alignment and ideal occlusion; the alterations emanated from bonding and adhesive removal procedures causes tooth color change [21] which is an essential aspect of smile esthetics; conversely, few studies have quantified the tooth color change related with orthodontic treatment which is the aim of this study.

The CIE $\mathrm{L}^{*} \mathrm{a} * \mathrm{~b} *$ color system is a reliable and repeatedly used approach in colorimetry [22] and therefore, in the present study, is used to measure the tooth color in an objective manner. $\Delta \mathrm{E}$ denotes the color difference between two objects and is calculated from colorimetric values 
( $\mathrm{L}^{*}, \mathrm{a}^{*}$ and $\mathrm{b}^{*}$ ). The average $\Delta \mathrm{E}$ difference of 3.7 has been reported to describe a color match in the oral environment [23]; hence, in the present study, the color difference beyond 3.7 units was considered as a clinically noticeable color change, keeping in mind that a difference of approximately one unit increases the probability of color detection by average observer [24]. Because of variable sensitivity of human eye to small color changes and the subjective nature of visual color detection, assessments in this study was performed by a spechtrophotometer to increase objectivity and reproducibility [25]. To decrease random errors multiple measurements were performed and averaged.

The effect of age on tooth color (becoming darker and more yellow) is negligible according to the short follow up interval [26].

Long-term color alterations occurred after debonding could be attributed to increased surface roughness and therefore stain susceptibility of the enamel $[27,28]$, and either extrinsic or intrinsic discoloration of the resin tags occupying acid-etched enamel rods $[6,29]$. Cleaning technique plays an important role in both the extent of resin elimination and final surface roughness [18]. Accordingly, in the present study, post debonding color change after two different techniques including $\mathrm{TC}$ as the common method and FC as a newly introduced method was assessed.

Statistically significant color alteration was observed in both groups with the mean value being above clinically detectable limit in TC group. these findings corroborate the result of Eliades et al who reported the clinically significant $\Delta \mathrm{E}$ in the debonding-ageing period [6]. However, Boncuk et al and Trakyali found negligible discoloration after debonding. This contradiction could be associated with the invitro design of these studies which included photo-aging that only resembles intrinsic discoloration $[21,30]$. Clinically significant color alteration was also reported by Ye et al after experimentally staining of debonded teeth [31].

Changes in CIE parameters exhibited significant increase in $L^{*}$ value and decrease in $b^{*}$ value in both groups while changes in $a^{*}$ were insignificant. The findings regarding $L^{*}$ and $b^{*}$ values are consistent with the results of Leibrock et al who reported the tendency of adhesive color change toward more yellow ( $\left.b^{*}\right)$ and darker $\left(\mathrm{L}^{*}\right)$ values [32]. Thus, the amount of discoloration could be partly controlled by choosing the most chemically stable adhesive resin.

The amount of $\Delta \mathrm{E}$ and changes in $\mathrm{L}^{*}$ and $\mathrm{b}^{*}$ values in FC group were less than TC group. in other words, discoloration after finishing with FC tends to be less yellow and dark. This finding is in agreement with the smoother surface achieved by FC which may provide better resin removal. A smoother surface also affects $L^{*}$ value which is sensitive to surface alteration and changes with surface roughness $[13,29]$. Caution should be exercised by taking into consideration that finishing with $\mathrm{FC}$ is more time-consuming when compared to TC [13].

The limitations of this study should be taken into consideration: systematic errors due to fault in the spectrophotometer device were unavoidable as $80 \%$ of the color assessments with Spectroshade were exact match according to shade tab measurements [22]. Another limitation is the external validity of the study which is lowered because of the single clinician performing the finishing process. There might also be a positive relationship between color change and the time passed after debonding; hence, a longer interval between debonding and follow up appointment would have demonstrated whether the difference between two groups worsens or not. Further research is also recommended with an expanded sample size.

\section{CONCLUSION}

Findings give the impression of an increased inevitable risk of long-term color change after debonding of orthodontic fixed appliance. The use of composite burs lowers this risk and it may be advantageous to use them 
despite the greater time consumed chair side. Apart from these recommendations, developing more efficient approaches regarding bonding and adhesive removal procedures remains as a matter of importance.

\section{Achnoledgements:}

None

\section{Fundings:}

None

\section{REFERENCES}

1. Tin-0o MM, Saddki N, Hassan N. Factors influencing patient satisfaction with dental appearance and treatments they desire to improve aesthetics. BMC oral health. 2011;11(1):6. doi:10.1186/1472-6831-11-6.

2. Arhun N, Arman A. Effects of Orthodontic Mechanics on Tooth Enamel:A Review.Semin Orthod. 2007;13(4):281-91. doi:10.1053/.j.sodo.2007.08.009.

3. Janiszewska-Olszowska J, Szatkiewicz T, Tomkowski R, Tandecka K, Grocholewicz K. Effect of orthodontic debonding and adhesive removal on the enamel - current knowledge and future perspectives - a systematic review. Medical science monitor : international medical journal of experimental and clinical research. 2014;20:1991-2001. doi:10.12659/MSM.890912.

4. Silverstone L, Saxton C, Dogon I, Fejerskov 0. Variation in the pattern of acid etching of human dental enamel examined by scanning electron microscopy. Caries Res. 1975;9(5):373-87. doi: 10.1159/000260179.

5. Al Maaitah EF,Omar AAA, Al-Khateeb SN. Effect of fixed orthodontic appliances bonded with different etching techniques on tooth color:a prospective clinical study. Am J Orthod Dentofacial Orthop. 2013;144(1):43-9. do: 10.1016/j.jajodo.2013.02.020

6. Eliades T,Kakaboura A, Eliades G, Bradley TG. Comparison of enamel colour changes associated with orthodontic bonding using two different adhesives. Eur J Orthod. 2001;23(1):85-90. doi:10.1093/ejo/23.1.85.

7. Sandison R. Tooth surface appearance after debonding. Br J Orthod. 1981;8(4):199-201. doi:10.1179/bjo.8.4.199.

8. Inokoshi S, Burrow M, Kataumi M, Yamada T, Takatsu T. Opacity and color changes of tooth-colored restorative materials. Oper Dent. 1996;21:73-80.

9. Karamouzos A, Athanasiou AE, Papadopoulos MA, Kolokithas G. Toothcolor assessment after orthodontic treatment: a prospective clinical trial. Am J Orthod Dentofacial Orthop. 2010;138(5):537.e1- e8. doi: 101016/j. ajodo.2010.03.026.

10. Chen Q, Zheng X, Chen W,NiZ,ZZhou Y. Influence of orthodontic treatment with fixed appliances on enamel color: a systematic review. BMC oral health. 2015;15(1):31. doi:101186/s12903-015-0014-x.

11. Cehreli ZC, Lakshmipathy M, Yazici R. Effect of different splint removal techniques on the surface roughness of human enamel: a three dimensional optical profilometry analysis. Dent Traumatol. 2008;24(2):177-82 doi: 10.1111/j.1600-9657.2007.00491.x.
12. Smith $S$, Walsh $L$, Taverne A. Removal of orthodontic bonding resin residues by CO2 laser radiation: surface effects. J Clin Laser Med Surg. 1999;17(1):13-8. doi: 10.1089/clm.1999.17.13.

13. Karan S, Kircelli BH, Tasdelen B. Enamel surface roughness after debonding: comparison of two different burs. Angle Orthod. 2010;80(6):1081-8. doi: 10.2319/012610-55.1.

14. AhrariF,Akbari M, Akbari J, Dabiri G. Enamel surface roughness after debonding of orthodontic brackets and various clean-up techniques. Journal of dentistry (Tehran, Iran). 2013;10(1):82.

15. Campbell PM. Enamel surfaces after orthodontic bracket debonding. Angle Orthod. 1995;65(2):103-10. doi:10.1043/0003-3219(1995)065«0103:ESAOBD» 2.0.C0;2.

16. Hosein I,Sherriff M, Ireland AJ. Enamel loss during bonding, debonding, and cleanup with use of a self-etching primer. Am J Orthod Dentofacial Orthop. 2004; $126(6): 717-24$.

17. Ireland A, Hosein I,Sherriff M. Enamel loss at bond-up, debond and clean-up following the use of a conventional light-cured composite and a resin-modified glass polyalkenoate cement. Eur J Orthod. 2005;27(4):413-9.

18. Zachrisson BU, Årthun J. Enamel surface appearance after various debonding techniques. Am J Orthod. 1979;75(2):121-37.

19. KaracaogluF, Tuzcel NY,Akkaya M. A Comperative Evaluation of 3 Different Polishing Methods on Tooth Surface Roughness. J Biomedical Sci. 2016, 6:1. doi:10.4172/2254-609X.100046

20. Kamber R, Papageorgiou SN, Eliades T.Does orthodontic treatment havea permanent effect on tooth color? Journal of Orofacial Orthopedics/Fortschritte der Kieferorthopädie. 2018;79(2):73-82. doi: 10.1007/s00056-018-0123-7.

21. Boncuk Y, Çehreli ZC, Polat-Özsoy Ö. Effects of different orthodontic adhesives and resin removal techniques on enamel color alteration. Angle Orthod. 2013;84(4):634-41. doi:10.2319/060613-433.1.

22. Kim-PusateriS, Brewer JD, Davis EL, Wee AG. Reliability and accuracy of four dental shade-matching devices. J Prosthet Dent. 2009;101(3):193-9. doi: 10.1016/S0022-3913(09)60028-7.

23. Johnston W, Kao E. Assessment of appearance match by visual observation and clinical colorimetry. J Dent Res. 1989;68(5):819-22. doi: 10.1177/00220345890680051301.

24. Seghi RR, HewlettE, Kim J. Visual and instrumental colorimetric assessments of small color differences on translucent dental porcelain. JDent Res. 1989;68(12):1760-4. doi: 10.1177/00220345890680120801.

25. Joo H-J, Lee Y-K, Lee D-Y, Kim Y-J, Lim Y-K. Influence of orthodontic adhesives and clean-up procedures on the stain susceptibility of enamel after debonding. Angle Orthod. 2011;81(2):334-40. doi: 10.2319/062610-350.1.

26. Joiner A. Tooth colour: a review of the literature.JDent. 2004;32:3-12. doi: 10.1016/j.jdent.2003.10.013

27. Özer T,Başaran G, Kama JD. Surface roughness of the restored enamel after orthodontic treatment. Am J Orthod Dentofacial Orthop. 2010;137(3):368-74. doi:10.1016/j.jojo.2008.02.025.

28. Berger SB, Palialol ARM, Cavalli V, Giannini M. Surface roughness and staining susceptibility of composite resins after finishing and polishing. J Esthet Restor Dent 2011;23(1):34-43. doi: 10.1111//1.1708-8240.2010.00376.x. 
29. Eliades T,Gioka C,Heim M,Eliades G, Makou M. Color stability of orthodontic adhesive resins. Angle 0rthod. 2004;74(3):391-3. doi: 10.1043/0003-3219(2004)074«0391:CSOOAR»2.0.C0;2.

30. Trakyall G, Özdemir Fl,Arun T.Enamel colour changes at debonding and after finishing procedures using five different adhesives. Eur $\mathrm{J}$ Orthod. 2009;31(4):397-401. doi:10.1093/ejo/cjp023.
31. Ye C,Zhao Z, Zhao Q, DuX, Ye J, WeiX. Comparison of enamel discoloration associated with bonding with three different orthodontic adhesives and cleaning-up with four different procedures. J Dent. 2013;41:e35-e40. doi: 10.1016/j.jdent.2013.07.012.

32 Leibrock A, Rosentritt M, Lang R,Behr M, Handel G. Colour stability of visible light-curing hybrid composites. Eur J Prosthodont Restor Dent. 1997;5(3):12530.

Tannaz Abdollahzadeh Baghaei

(Corresponding address)

Golgasht Ave, Tabriz, IRAN.

Date submitted: 2020 Mar 30

E-mail: tannazabdz@gmail.com

Accept submission: 2020 Jun 08 